\title{
Temperature gradient and initial snow density as controlling factors in the formation and structure of hard depth hoar
}

\author{
W. TAD PFEFFER, ${ }^{1}$ RANDY MRUGALA ${ }^{2}$ \\ ${ }^{1}$ Institute of Arctic and Alpine Research and Department of Civil, Environmental, and Architectural Engineering, University of Colorado, \\ Boulder, Colorado 80309-0450, U.S.A. \\ E-mail:pfeffer@tintin.colorado.edu \\ ${ }^{2}$ Institute of Arctic and Alpine Research and Department of Geological Sciences, University of Colorado, Boulder, Colorado 80309-0450, U.S.A.
}

\begin{abstract}
We investigate how temperature gradient and initial density influence depth-hoar growth in snow and seek to better define the range of conditions under which cohesive, or hard, depth hoar forms. Samples of $400 \mathrm{~kg} \mathrm{~m}^{-3}$ sieved snow were exposed to temperature gradients of $20-80^{\circ} \mathrm{C} \mathrm{m}^{-1}$, and samples of four different densities were exposed to a $40^{\circ} \mathrm{C} \mathrm{m}^{-9}$ temperature gradient. Following exposure to temperature gradients, penetrometer tests were made on samples to determine the presence of solid and/or hard depth hoar. Grain bond orientation was analyzed in section planes by two-dimensional stereological techniques where hard depth hoar developed. Results indicate that hard cohesive depth hoar forms from rounded-grain snow having a density of $400 \mathrm{~kg} \mathrm{~m}^{-3}$ or greater, following exposure to a temperature gradient of $20^{\circ} \mathrm{C} \mathrm{m}^{-1}$ or greater. Hard depth hoar appears to consist of solid-type depth-hoar grains connected by necks, with vertically preferred directions of grain elongation and organization of grain-to-grain chains. This work corroborates Atikaya's (1974) results, but extends his observation of formation of hard depth hoar to weaker temperature gradients for high-density snow. Our results also indicate that hard depth hoar is composed of faceted solid-type (anhedral) grains.
\end{abstract}

\section{INTRODUGTION}

Kinetic growth processes in deposited snow exposed to spatial temperature gradients cause significant changes in seasonal snowpack and multi-year firn characteristics. Among the effects of these changes, the most significant is perhaps the formation of incohesive layers of altered crystals (depth hoar) in continental alpine snowpacks which reduce the strength of the snowpack along laterally extensive horizons and are a primary precursor to dry-slab avalanche release. Alteration occurs under conditions of strong vapor transport along a temperature gradient at or greater than $\sim 10^{\circ} \mathrm{C} \mathrm{m}^{-1}$, typically created by a thin snowpack ( $1 \mathrm{~m}$ and less) separating a warm ground surface $\left(\sim 0^{\circ} \mathrm{C}\right)$ from cold air, although grain-size, texture and initial density are also factors. The grain-scale processes responsible for kinetic grain growth are generally well known and we do not discuss them here. Detailed analyses are given by Colbeck (1983), Perla (1985) and Perla and Ommanney (1985); a general review of heat and mass transfer in dry snow is given by Arons and Colbeck (1995). Another situation where kinetic growth forms are important occurs in multi-year polar firn, where fall deposition of surface hoar is commonly used as a visual marker horizon separating annual layers (Alley and others, 1990). Low-density kinetic growth horizons and heterogeneous firn layering also influence heatand vapor-transport properties and influence diagenetic alteration of distributions of paleoclimatically significant tracers in ice cores (Cuffey and Steig, 1998).

Kinetically altered grains that make up depth hoar are classified morphologically according to their stage of development. Solid-type depth-hoar grains are solid grains having flat surfaces and sharp corners, while skeleton-type depth-hoar grains exhibit well-developed stepped surfaces and often form cup-like shapes (Sommerfeld and LaChapelle, 1970; Akitaya, 1974). These types of depth hoar are also respectively referred to as anhedral and euhedral depth-hoar grains (Bradley and others, 1977). Both solid- and skeleton-type depth hoar produce weak layers owing to large grain-sizes (typically $>1 \mathrm{~mm}$ ) and sparse grain-to-grain bonding, and it is this weakness that makes depth-hoar layers so important in dryslab avalanche mechanics. Laboratory work by Akitaya (1974) showed that a third very hard cohesive type of depth hoar (hard depth hoar) formed when high-density $(\rho)$ snow $\left(\rho>300 \mathrm{~kg} \mathrm{~m}^{-3}\right)$ with a mean temperature of $-7^{\circ} \mathrm{C}$ was exposed to temperature gradients $>39^{\circ} \mathrm{C} \mathrm{m}^{-1}$. Hard depth hoar shows much greater strength characteristics than the solid and skeleton forms, and a better knowledge of the conditions under which it forms is of value in improving understanding of avalanche mechanics.

Snow texture (the grain and pore shapes, sizes, orientations and grain attachments which characterize a given snowpack) is also altered by diagenetic processes like kinetic grain growth, and these changes create further complexity in the heat- and vapor-transfer characteristics of the snow. Snow texture is generally anisotropic, but the degree of anisotropy is accentuated by kinetic growth forms. Stereological methods performed on plane sections cut from castings of snow have been applied to characterize the grain-scale structure, but it is difficult to make generalizations about three-dimensional (3-D) snow structure on the basis of two-dimensional (2-D) observations (Arons and Colbeck, 1995). Some fully 3-D analyses have been made (e.g. Brzoska 


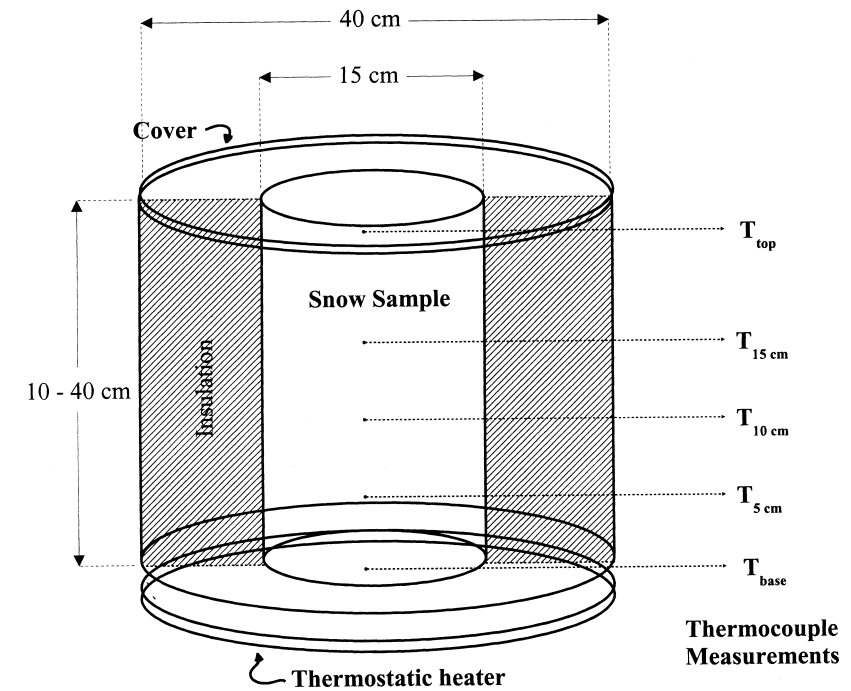

Fig. 1: Schematic of experimental apparatus.

and others, 1999), but these are extremely time-consuming. In the present work we address the 3-D character of snow texture to the extent that we compare analyses of sections cut perpendicular and parallel to the direction of the applied temperature gradient, but we exercise caution in generalizing our stereological results.

The work presented here consists of a series of laboratory experiments in which we investigated how the magnitude of temperature gradient and the initial snow density control the type of depth hoar that forms within snow samples. Our purpose was to develop hard depth hoar in a laboratory setting and attempt to more clearly define the range of conditions (principally initial density and imposed temperature gradient) which favor its formation over the formation of incohesive depth hoar. Samples of high-density $\left(400 \mathrm{~kg} \mathrm{~m}^{-3}\right)$ sieved snow were exposed to four different temperature gradients, and snow samples of four different types and densities were exposed to a $40^{\circ} \mathrm{C} \mathrm{m}^{-1}$ temperature gradient. In addition to sieved snow and samples from natural snowpacks, samples were taken from the base of a snowpack that had been continuously compacted by snowmobiles throughout a winter season. Following exposure to a controlled temperature gradient, penetrometer tests were made on the samples to determine the presence of solid and/or hard depth hoar. If hard depth hoar was present, the orientation of grain-to-grain bonds was analyzed in section planes by simple 2-D stereological techniques.

\section{METHODS}

\section{Experimental apparatus}

Snow was exposed to controlled temperature gradients by placing samples in laterally insulated containers and controlling the end temperatures. The magnitude of the applied temperature gradient was achieved primarily by choosing the sample length appropriately, and maintaining end temperatures at fixed values. Insulated cylindrical polyurethane plastic tubes were used to house snow samples. The cylinders were $15 \mathrm{~cm}$ in diameter and variable in height. Experiments were conducted in a thermostatically controlled cold room (with ambient room temperature maintained at $\sim-10^{\circ} \mathrm{C}$, relative humidity $52 \%$ relative to water). The columns were insulated laterally in a $40 \mathrm{~cm}$ wide Styrofoam box, with only the ends exposed (Fig. 1). The top of the column was in thermal con- tact with the ambient cold-room temperature but sealed from substantial vapor loss by a metal plate, while the bottom of the column was maintained at $\sim-2^{\circ} \mathrm{C}$ by a thermostatically controlled hot plate. A thin sheet of Styrofoam inserted between the sample base and the hot plate helped to buffer the base of the snow column from spiky temperature changes as the hot-plate thermostat cycled. Thermostatic cycling in the cold room caused $\sim \pm 4^{\circ} \mathrm{C}$ variations in room air temperature (and consequent changes in relative humidity) on sub-hourly time-scales. Effects of variations in room water vapor were minimized by the metal plate on the top of the column, but the temperature variations carried conductively into the top of the column would also force changes in relative humidity within the column. For this reason, the temperature gradient was calculated near the base of the column (between 5 and $10 \mathrm{~cm}$ and 10 and $15 \mathrm{~cm}$ measured from the sample base), and all samples cut for analysis were taken from this region.

Snow temperatures were monitored with type T 25 AWG thermocouples placed in the snow samples at regular vertical intervals in the center of the column with thermocouple wires brought in horizontally. Air temperature was measured by a thermocouple at the upper surface of the snow. The temperature at the base of the snow was monitored with a thermistor. A thermistor was also used to measure reference temperature at the datalogger panel. The datalogger was placed in an insulated container in order to stabilize the reference thermistor from changes imposed by the varying room temperature. The nominal accuracy of the temperature measurements is $\pm 0.2^{\circ} \mathrm{C}$.

Cast section planes were prepared according to methods described in Perla (1982). Diethyl phthalate was used as a pore filler in preparation of the section planes.

Horizontal and vertical section planes were prepared and photographed before and after experimental runs for the purpose of analyzing grain-size, grain shape, and orientation of grain-to-grain bonds.

Individual snow grains and section planes prepared from snow samples were photographed in reflected light on $35 \mathrm{~mm}$ Kodak Plus-X film with a Wild M5 stereo microscope equipped with a Wild Mkal photomicrographic camera. Negatives were scanned at $600 \mathrm{dpi}$, with corresponding resolution in the object space of $\sim 198$ pixels $\mathrm{mm}^{-1}$. The images were manipulated in Photoshop to enhance the separation of grain images from pore filler, but difficulty was encountered in grain image separation because the section-polishing method used (abrasive cloth) left striations on the section surface which persist in the images. Consequently, digital analysis was not possible, and stereological measurements were made manually on prints, by standard methods as described, for example, in Underwood (1970).

\section{EXPERIMENTAL PROGEDURE}

\section{Imposed temperature-gradient experiments}

Four samples of high-density $\left(400 \mathrm{~kg} \mathrm{~m}^{-3}\right)$, rounded-grain, sieved snow were exposed to various temperature gradients, each for a period of 3 days. Snow for these experiments was collected from mountain locations near our Boulder laboratory and stored at $-10^{\circ} \mathrm{C}$ or less prior to use. Sieving of snow into the test columns was done at low temperatures to reduce sintering in the snow column. Care was taken in sieving to insure a uniform snow texture, and grain diameter measurements were made to confirm an initially uniform and isotro- 

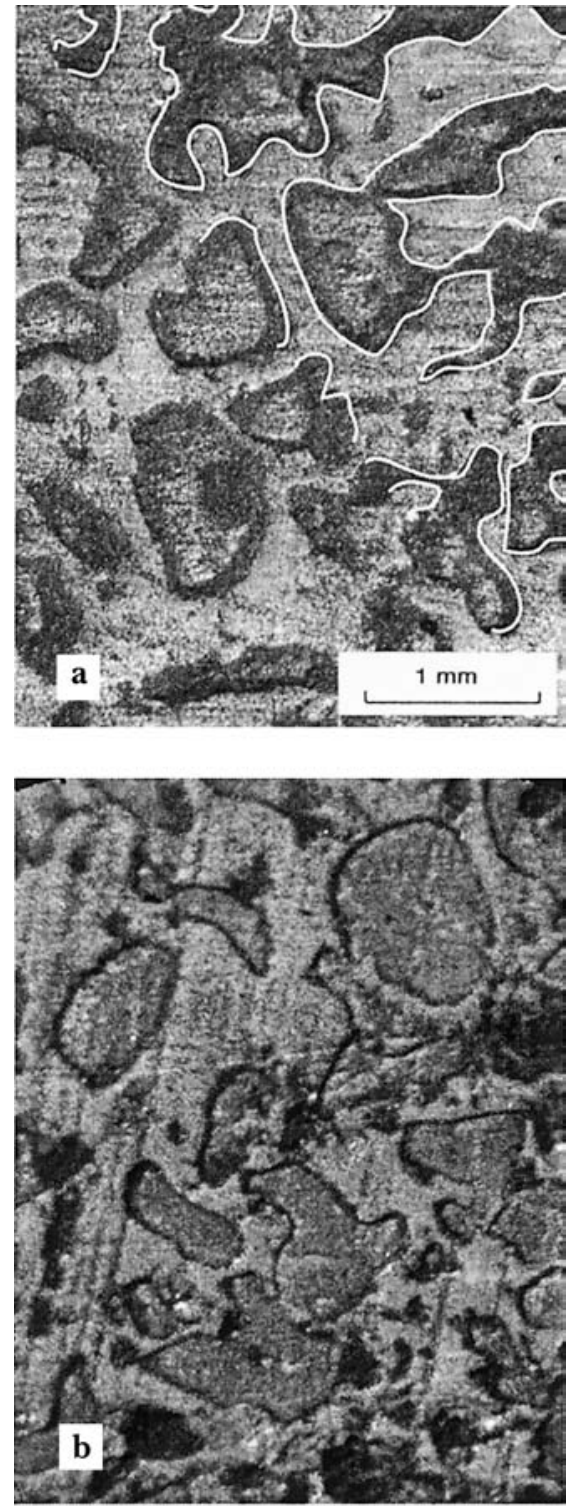

Fig. 2. Snow grains from high-density, sieved snow prior to experimental runs. Mean snow density is $400 \mathrm{~kg} \mathrm{~m}^{-3}$. Section plane $A$ is cut from the longitudinal (vertical) axis of the cast; section plane $B$ is cut from the horizontal plane. Grains are outlined in one half of section plane $A$.

Table 1. Initial grain-size for sieved snow samples

\begin{tabular}{lccc}
\hline $\begin{array}{l}\text { Sample orientation and } \\
\text { measurement direction }\end{array}$ & $\begin{array}{c}\text { Mean grain } \\
\text { diameter } \\
\bar{d}\end{array}$ & $\begin{array}{c}\text { Grain diameter } \\
\text { standard deviation }\end{array}$ & $\begin{array}{c}\text { Sample } \\
\text { size } \\
\text { mm }\end{array}$ \\
& 0.303 & 0.181 & 65 \\
\hline $\begin{array}{l}\text { Vertically oriented section, } \\
\text { grain diameter measured } \\
\text { in horizontal direction }\end{array}$ & & & \\
$\begin{array}{l}\text { Vertically oriented section, } \\
\text { grain diameter measured } \\
\text { in vertical direction }\end{array}$ & 0.325 & 0.204 & 59 \\
$\begin{array}{l}\text { Horizontally oriented section, } \\
\text { grain diameter measured in } \\
\text { horizontal direction on image }\end{array}$ & 0.269 & 0.200 & 74 \\
$\begin{array}{l}\text { Horizontal oriented section, } \\
\text { grain diameter measured in } \\
\text { vertical direction on image }\end{array}$ & 0.256 & 0.189 & \\
\hline
\end{tabular}

pic grain-size. Figure 2 shows typical initial snow textures on sections oriented horizontally and vertically (i.e. parallel and perpendicular to the applied temperature gradient), and Table 1 shows summary statistics of grain diameter measurements based on grain/grid intersection lengths made on sections cut in directions oriented vertically and horizontally. Within each section, measurements were made in two mutually perpendicular directions. Grain-size was quantified by grain diameter in section planes, and was measured by grain-boundary/gridline intersection lengths on section plane images. The mean grain-sizes for the four sections differ by a maximum of $0.069 \mathrm{~mm}$, which is approximately $3 \%$ of the average standard deviation of the four means, and we infer that no initially organized grain elongation or preferred direction of elongation exists in the snow columns. The average initial grain-size for all measurements taken as a single sample is $0.28 \pm 0.19 \mathrm{~mm}$.

In addition to the four sieved snow samples, three different initial snow types were collected in the field and transported, with sample orientation preserved, back to the laboratory. These three samples, along with a fourth made up of sieved snow, were each exposed to a $40^{\circ} \mathrm{C} \mathrm{m}^{-1}$ temperature gradient. The initial snow types and initial and final densities for this series of experiments are given in Table 2.

Kinetic grain development was also investigated at the base of a snowpack that had been compacted by snowmobiles for an entire winter. Maintaining original orientation, snow samples were transported back to the cold room for analysis. Horizontal and vertical section planes were prepared and photographed. The sampling area, located at the University of Colorado Mountain Research Station, had an elevation of $2900 \mathrm{~m}$, an easterly aspect, and a slope of approximately $10^{\circ}$.

Finally, one $20 \mathrm{~cm}$ column of snow was allowed to remain isothermal $\left(T=-10^{\circ} \mathrm{C}\right)$ in an insulated container for 3 days and was subsequently compared to the samples exposed to temperature gradients.

\section{Development of preferred grain-size and grain orientation}

From observations in natural snowpacks, grain-size and shape change during metamorphism. Grains tend to enlarge under the influence of kinetic growth conditions, and grain texture, especially within polar multi-year firn, suggests that grain elongation occurs in the direction parallel to vapor transport. We sought to quantify these changes in the experimental samples. It will be seen in the figures showing section planes that the grain geometry (and grain-to-grain bonds in particular) is not fully represented by single sections. This is most obvious in low-density samples where many individual grains have no connection with any neighbor in the section,

Table 2. Original type and density of snow exposed to a $40^{\circ} \mathrm{Cm}^{-1}$ temperature gradient

\begin{tabular}{lcc}
\hline Snow type & $\begin{array}{c}\text { Initial snow } \\
\text { density } \\
\mathrm{kg} \mathrm{m}^{-3}\end{array}$ & $\begin{array}{c}\text { Final snow } \\
\text { density } \\
\mathrm{kg} \mathrm{m}^{-3}\end{array}$ \\
\hline Fresh snow: rimed stellar crystals with dendrites & 32 & 123 \\
Boot-packed fresh snow & 192 & $\mathrm{n} / \mathrm{a}$ \\
Rounded-grain snow from alpine snowpack & 230 & 266 \\
Sieved rounded-grain snow, 1.6 mm sieve & 400 & 396 \\
\hline
\end{tabular}


implying that the sample integrity is maintained by grainto-grain bonds lying outside of the section. The 3-D grain structure and features such as anisotropy can be deduced only to a limited degree from 2-D plane sections, and inferences using classic stereological techniques (e.g. Underwood, 1970) are only valid under assumptions of geometric regularity of grains (Good, 1987, 1989). However, some information on grain structure can be derived from collections of 2-D sections by comparing measurements of grain elongation from sections made at different orientations in the sample column. Better grain-scale characterization can be accomplished by high-resolution serial sectioning but was not done here. Instead, we rely on mutually perpendicular sections to reveal structures lying outside the plane of a single section. The observations analyzed here are typically made on length scales of the section images (typically 3$5 \mathrm{~mm}$ ); this length scale appears to be larger than the length scale of microstructural grain/pore variation but small enough to be a geostatistically stationary sample (Bloeschel, 1999), and we take this length scale to be the representative elementary volume (REV) as defined by Bear (1988). We note, however, that while this length scale may represent local structural characteristics adequately, phenomena such as vapor transport are strongly influenced by heterogeneity in structure, and accurate modeling of such phenomena requires knowledge of the variations of structural properties over length scales larger than our REV.

Photographs of section planes that showed visual evidence of grain elongation were analyzed for degree of orientation $(\Omega)$ according to line intersection methods described in Underwood (1970), where

$$
\Omega=\frac{P_{\mathrm{n}}-P_{\mathrm{p}}}{P_{\mathrm{n}}+0.571 P_{\mathrm{p}}} .
$$

The number of grain-boundary/gridline intersections per millimeter with gridlines oriented parallel to a chosen axis (in this case the direction of the vapor flux gradient) is represented by $P_{\mathrm{p}}$, while $P_{\mathrm{n}}$ represents the number of line intersections per millimeter with lines oriented normal to that axis. The value $\Omega$ is typically expressed as a percentage and gives a measure of preferred orientation with respect to the chosen axis; its value will approach zero for grain fab-

Table 3. Grain diameter before and after experimental runs. Average grain-sizes are shown for vertical (parallel to vapor flux) and horizontal (perpendicular to vapor flux) orientations before exposure to temperature gradient, and also for vertical and horizontal orientations after exposure, for the four temperature gradients applied

Grain-size before exposure to temperature gradient ( $\mathrm{mm}$ )

$$
\begin{array}{cc}
\text { Vertical section } & \text { Horizontal section } \\
0.313 & 0.262
\end{array}
$$

Grain Size following exposure to temperature gradient ( $\mathrm{mm}$ )

\begin{tabular}{cccc}
\multicolumn{2}{c}{ Vertical section } & \multicolumn{2}{c}{ Horizontal section } \\
$\nabla T$ & $\bar{D}$ & $\nabla T$ & $\bar{D}$ \\
${ }^{\circ} \mathrm{C} \mathrm{m}^{-1}$ & $\mathrm{~mm}$ & ${ }^{\circ} \mathrm{C} \mathrm{m}^{-1}$ & $\mathrm{~mm}$ \\
& & & \\
\hline 0 & 0.562 & 20 & 0.596 \\
20 & 0.592 & 40 & 0.554 \\
40 & 0.717 & 80 & 0.414 \\
80 & 0.552 & 80 & 0.488 \\
\hline
\end{tabular}

rics having no preferred orientation whatever, and approaches $100 \%$ for a grain structure highly oriented in the direction of the chosen axis.

Measurements of $\Omega$ were made on section casts from samples exposed to temperature gradients of $0,20,40$ and $80^{\circ} \mathrm{C} \mathrm{m}^{-1}$. For each temperature gradient, measurements were made on sections cut on planes parallel to the direction of the applied temperature gradient (that is, on planes containing the gradient vector), and also on planes cut perpendicular to the applied temperature gradient.

Mean grain diameter within section planes (averaged over all gridline orientations for the section) is shown in Table 3.

\section{Strength and hardness}

Hardness values are used as a proxy for strength. Hardness before and after experimental runs is given in terms of the International Commission on Snow and Ice (ICSI) handhardness scale (Colbeck and others, 1990) values between R1 and R4, while hardness of R5 or greater was measured with a flat-ended $8 \mathrm{~mm}$ diameter penetrometer adapted with a spring scale. Sections of $125 \mathrm{~cm}^{3}$ volume were cut from the columns at $0-5$ and $5-10 \mathrm{~cm}$ heights (measured from bottom of the sample) for testing with this apparatus.

\section{RESULTS}

Effects of varying temperature gradient across highdensity sieved snow samples

Prior to experimental runs, sieved snow had an initial ICSI hand hardness of R2, and snow grains were rounded with diameters ranging from 0.3 to $1.0 \mathrm{~mm}$ (Fig. 2; Table 1). Hard depth hoar formed in all samples of $400 \mathrm{~kg} \mathrm{~m}^{-3}$ snow that were exposed to a temperature gradient. Necks formed between individual faceted depth-hoar grains, linking the grains into chains oriented with their long axes parallel to the direction of vapor flux. Figure 3 shows plane-section casts cut parallel to the vapor-transport direction following exposure to four temperature gradients ranging from 0 to $80^{\circ} \mathrm{Cm}^{-1}$. Figure 4 shows plane-section casts cut normal to the vapor-transport direction. In Figure 3, grains elongated parallel to the direction of vapor flux are present in the sections subjected to temperature gradients of 20,40 and $80^{\circ} \mathrm{C} \mathrm{m}^{-1}$, with the elongation being more obvious at higher temperature gradients. Elongated grains are not evident in the horizontal sections of Figure 4. Figure 5 shows line-intersection analyses of the sections shown in Figures 3 and 4. The degree of orientation, as measured by $\Omega$, is indeed best developed in the vertical direction, parallel to vapor transport, with the degree of preferred orientation increasing with increasing temperature gradient.

One expression of the limitations of 2-D analyses of 3-D grain distributions is clearly visible in Figures 3 and 4. Few grain-to-grain bonds are visible in the section plane of the sample that was allowed to remain isothermal (Figs $3 \mathrm{a}$ and 4a). Since the cohesion of the sample was maintained as it was removed from the sample tube, grain-to-grain bonds were evidently present but not represented in the particular plane exposed in the section. Multiple parallel sections would clearly give a better representation of grain shape and connectivity, but this level of analysis was beyond the scope of this study. This limitation points to the need for comprehensive 3-D sampling and analysis, and efficient methods for performing such analyses. 

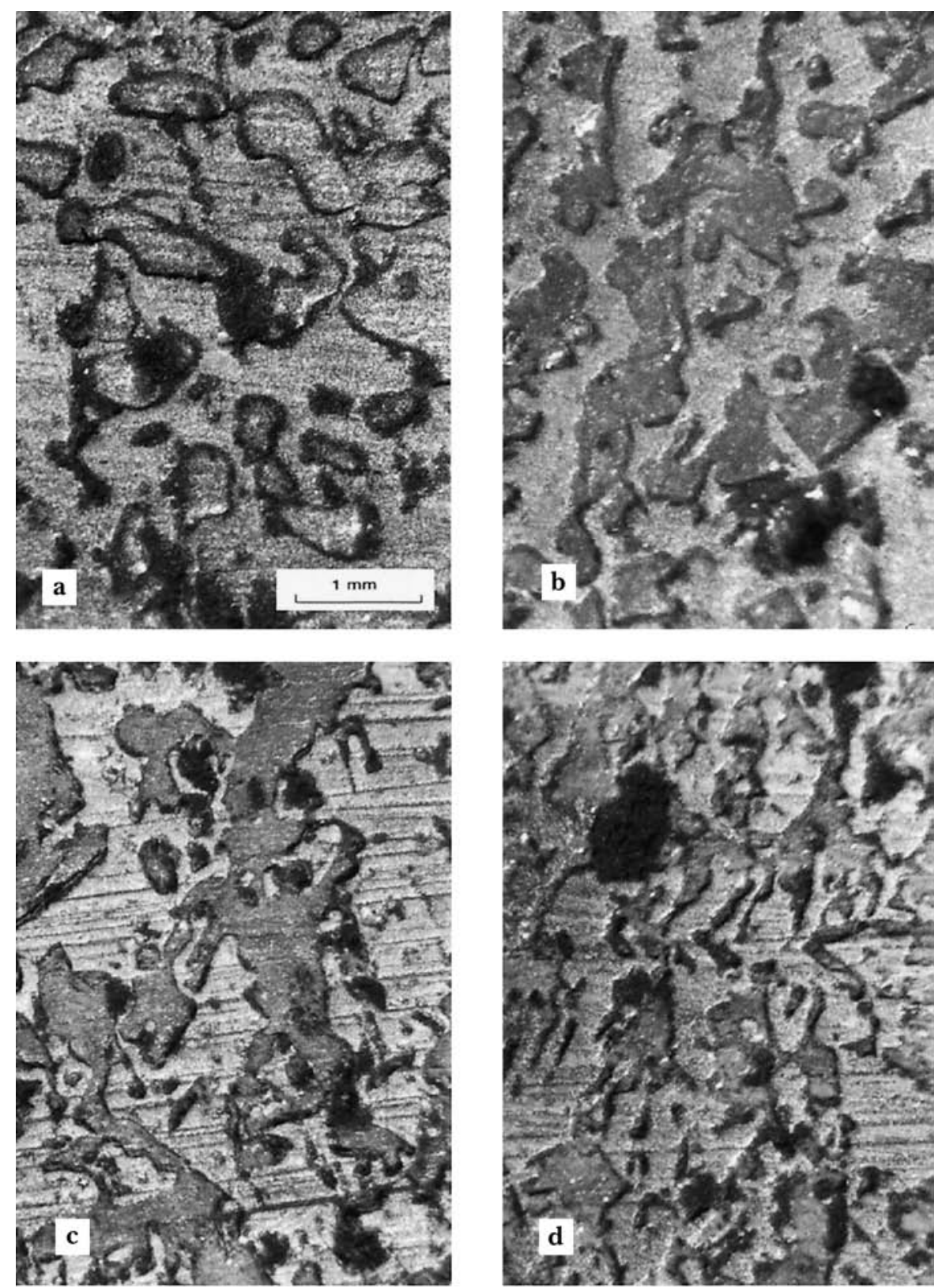

Fig. 3. Effect of varying temperature gradient through high-density snow. Orientation of section planes is parallel to the direction of vapor flux. The orientation of the temperature gradient is vertical and up (heat flowing from bottom to top). Mean initial snow density was $400 \mathrm{~kg} \mathrm{~m}^{-3}$. (a) Isothermal; (b) $20^{\circ} \mathrm{Cm}^{-1}$; (c) $40^{\circ} \mathrm{Cm}^{-1}$; (d) $80^{\circ} \mathrm{Cm}^{-1}$.

\section{Hardness}

Sample hardness following exposure to a temperature gradient is well correlated to the magnitude of the applied temperature gradient. Figure 6 shows hardness as determined by penetrometer as a function of applied temperature gradient, with hardness measured at two levels $(0-5$ and 5$10 \mathrm{~cm}$, measured from the base of the sample). A correlation coefficient $r^{2}$ of approximately 0.95 was calculated for a linear regression line relating hardness and temperature gradient for both levels.

\section{Effect of varying initial snow density}

Of the four snow samples of differing densities that were exposed to a $40^{\circ} \mathrm{C} \mathrm{m}^{-1}$ temperature gradient, the formation of hard depth hoar was evident only in the $400 \mathrm{~kg} \mathrm{~m}^{-3}$ sample, where hardness increased from ICSI R2 to R 5 following application of the temperature gradient. At lower densities, sintering and alteration occurred, but hardness was not increased. Sintering was sufficient in the sample of $230 \mathrm{~kg} \mathrm{~m}^{-3}$ rounded-grain snow for its integrity to be maintained as it was removed from the sample tube, and hardness in this case increased from ICSI R2 to R4. Figure 7 shows section casts from the $230 \mathrm{~kg} \mathrm{~m}^{-3}$ test, cut parallel to the vapor-transport direction before and after application of the temperature gradient. Grain growth is evident, but not grain elongation or substantial neck development. Figure 8 shows the same test sample before and after application of the temperature gradient with the plane sections oriented normal to vapor transport. Little evidence of neck formation between grains was observed in the section planes from this sample, although some faceting was observed.

Incohesive solid-type depth hoar formed in the low-density samples of fresh snow $\left(32 \mathrm{~kg} \mathrm{~m}^{-3}\right)$ and boot-packed fresh snow $\left(192 \mathrm{~kg} \mathrm{~m}^{-3}\right)$. The low-density fresh snow was captured as precipitation in the sample holder, and the boot-packed snow was sampled in the field. Both were transported to 

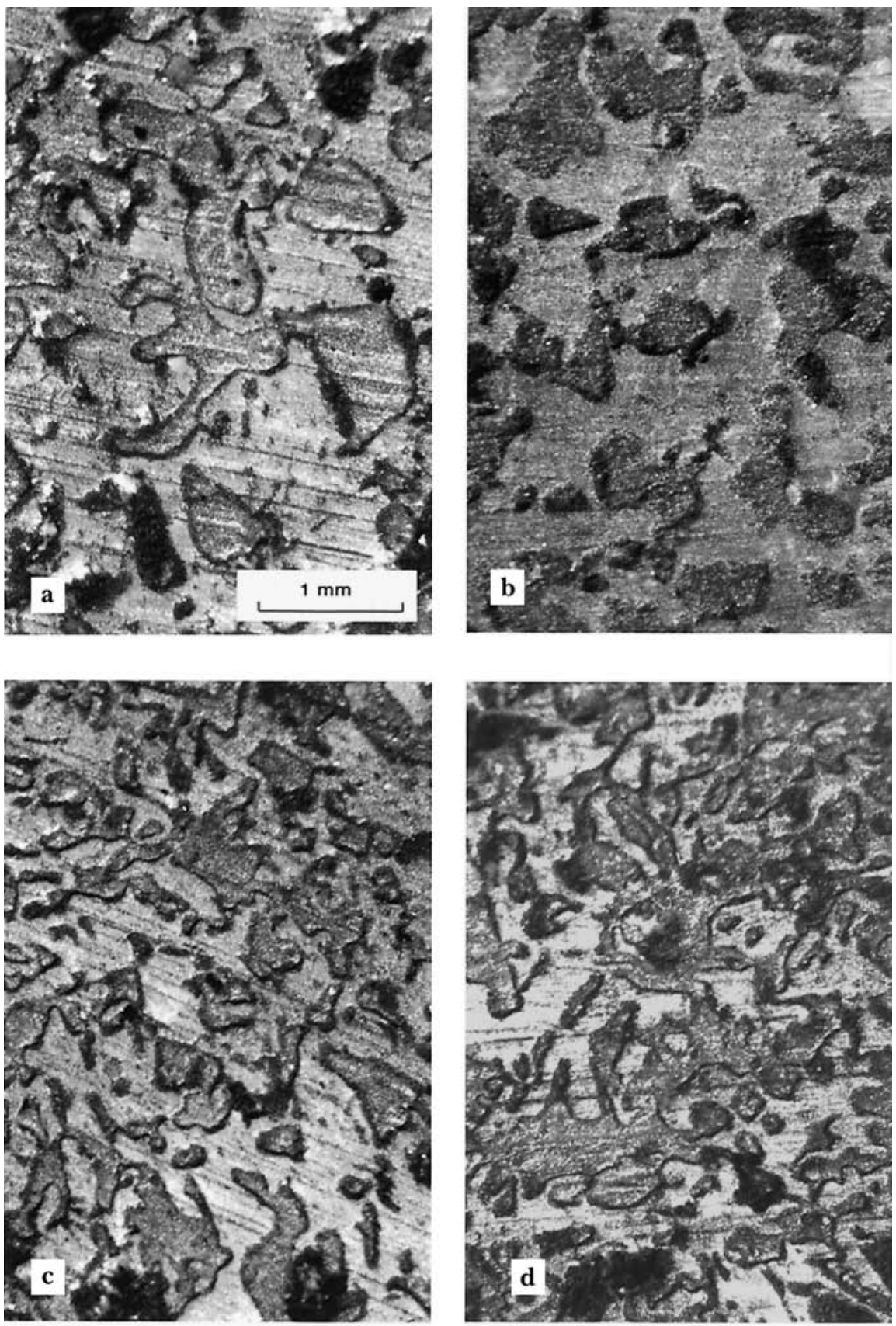

Fig. 4. Effect of varying temperature gradient through high-density snow. Orientation of section planes is normal to the direction of vapor flux. Mean initial snow density was $400 \mathrm{~kg} \mathrm{~m}^{-3}$. (a) Isothermal; (b) $20^{\circ} \mathrm{Cm}^{-1}$; (c) $40^{\circ} \mathrm{Cm}^{-1}$; (d) $80^{\circ} \mathrm{C} \mathrm{m}^{-1}$.

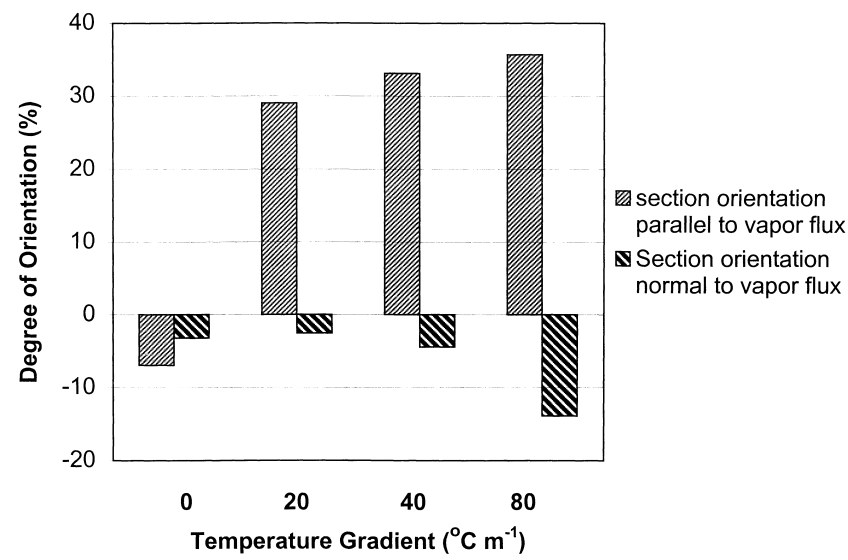

Fig. 5. Effect of varying temperature gradient on degree of orientation. Positive values for degree of orientation indicate preferred orientation is parallel to vapor flux.

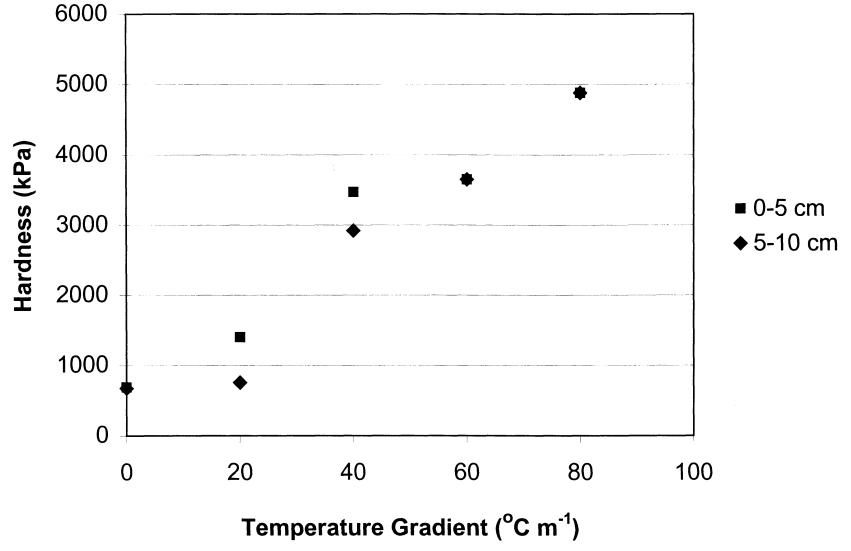

Fig. 6. Final snow hardness of $125 \mathrm{~cm}^{3}$ blocks of snow taken from the 0-5 and 5-10 cm levels of snow samples. Measured hardness indicates point of brittle failure of the snow sections. 

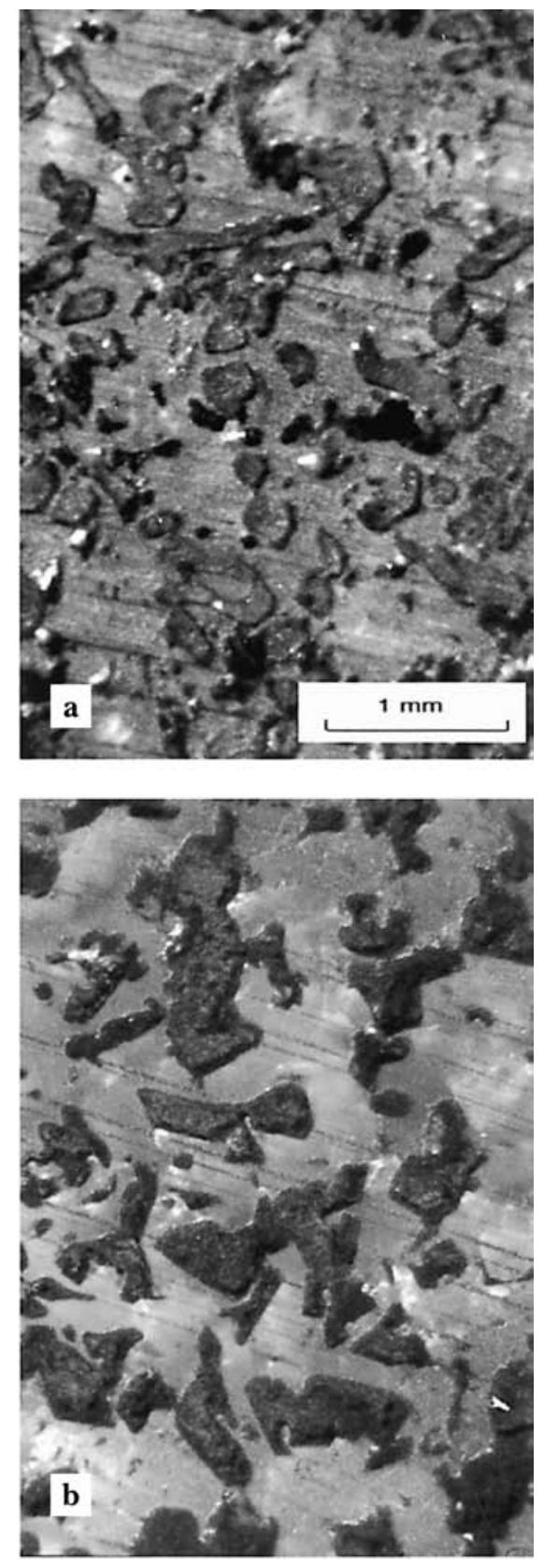

Fig. 7. Effect of exposing $230 \mathrm{~kg} \mathrm{~m}^{-3}$ rounded-grain snow to a $40^{\circ} \mathrm{Cm}^{-1}$ temperature gradient for 3 days. Orientation of section planes is parallel to the direction of vapor flux. The orientation of the temperature gradient is vertical and up (heat flowing from bottom to top). (a) Before exposure to $40^{\circ} \mathrm{Cm}^{-1}$; (b) after exposure to $40^{\circ} \mathrm{Cm}^{-1}$.

the laboratory in an insulated box. The snow in both of these samples remained very incohesive following exposure to the applied temperature gradient, and the ICSI hardness did not change from its initial value of $\mathrm{R}$, although casting was possible. Figure 9 shows the $32 \mathrm{~kg} \mathrm{~m}^{-3}$ sample following exposure to the applied temperature gradient.

Figure 10 shows the change in ICSI hardness following application of the $40^{\circ} \mathrm{C} \mathrm{m}^{-1}$ temperature gradient for the four snow samples described above.

\section{Effects of compaction}

Figure 11 shows that hard depth hoar formed in the compacted snow under the snowmobile trail. Bonded chains of grains, having a morphology very similar to chains of grains observed in laboratory experiments, were observed
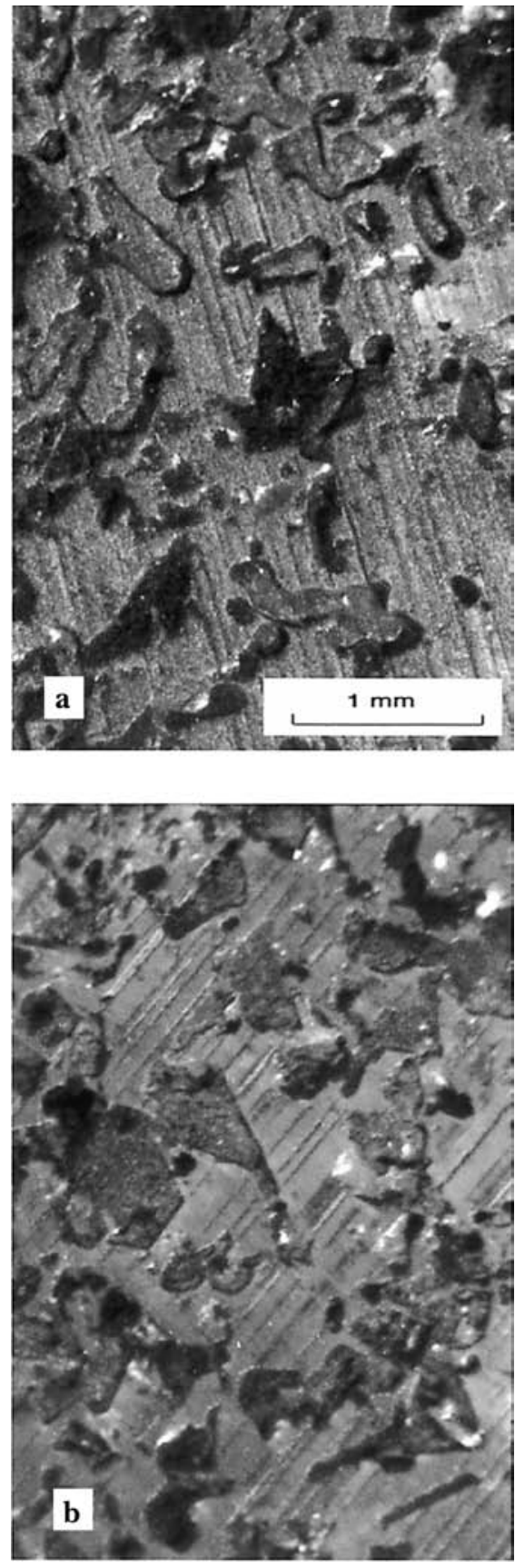

Fig. 8. Effect of exposing $230 \mathrm{~kg} \mathrm{~m}^{-3}$ rounded-grain snow to a $40^{\circ} \mathrm{Cm}^{-1}$ temperature gradient for 3 days. Orientation of section planes is normal to the direction of vapor flux. (a) Before exposure to $40^{\circ} \mathrm{Cm}^{-1}$; (b) after exposure to $40^{\circ} \mathrm{Cm}^{-1}$.

in the section plane of snow that was oriented parallel to vapor transport. Angular and faceted depth-hoar grains were observed in the section plane that was oriented normal to vapor transport; however, no preferred orientation of grain-to-grain bonding was observed in this section plane.

\section{DISGUSSION}

\section{Effect of temperature gradient on the formation of depth hoar}

Judging from analysis of 2-D section planes and individual depth-hoar grains, hard depth hoar appears to consist of solid-type depth-hoar grains connected by necks, with vertically preferred directions of grain elongation and organization of grain-to-grain chains. The preferred orientation of grain-to- 


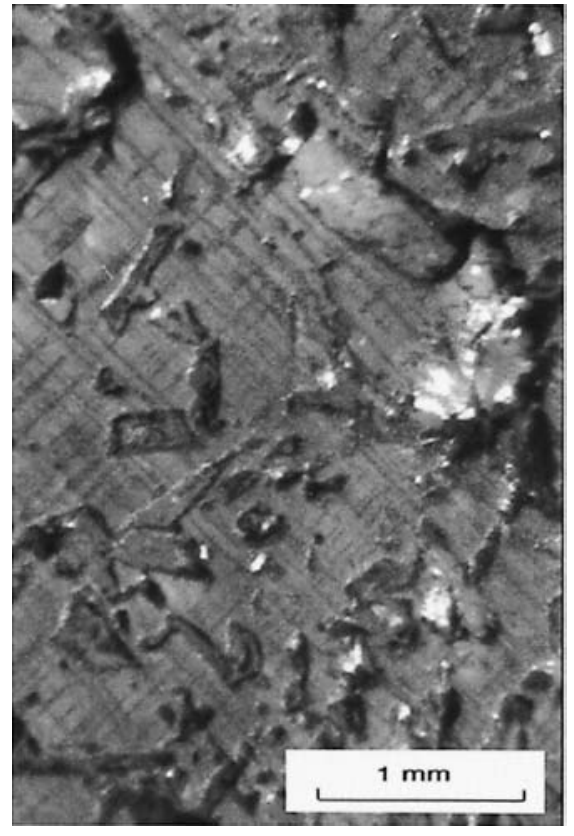

Fig. 9. Section plane of solid-type depth-hoar grains. Effect of exposing fresh snow (stellar crystals, original density = $32 \mathrm{~kg} \mathrm{~m}^{-3}$ ) to a $40^{\circ} \mathrm{Cm}^{-1}$ temperature gradient for 3 days. The orientation of grains within the section plane is random.

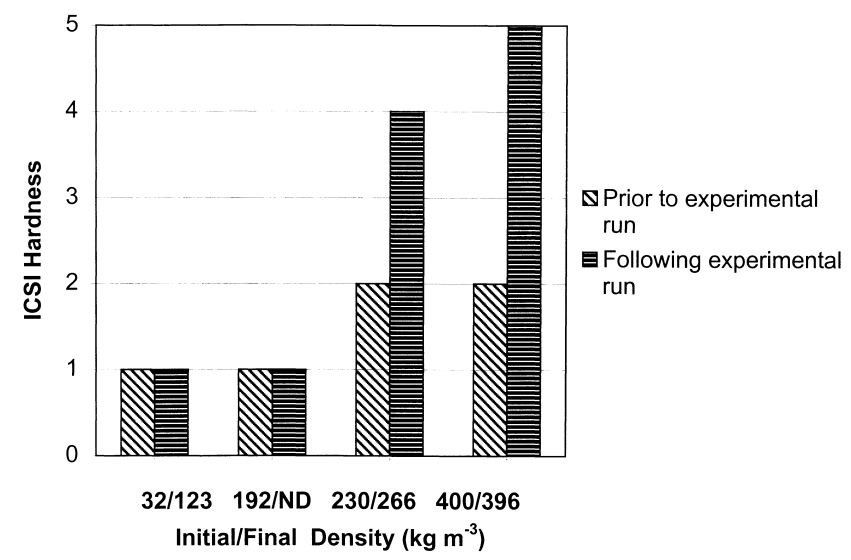

Fig. 10. ICSI hardnesses and the types of depth hoar that formed in snow samples of varying density.

grain bonds in the direction parallel to vapor transport indicates that neck formation is dependent on vapor flux and therefore is also dependent on temperature gradient. We note that 2-D observations do not lead to firm inferences about 3-D structure, and emphasize that the observations presented here are compatible with the 3-D structures proposed but do not entirely confirm the presence of those structures.

Hard depth hoar formed in high-density $\left(400 \mathrm{~kg} \mathrm{~m}^{-3}\right)$ sieved snow samples at all four of the induced temperature gradients $\left(20,40,60\right.$ and $\left.80^{\circ} \mathrm{C} \mathrm{m}^{-1}\right)$, and the hardness was well correlated with the magnitude of the applied temperature gradient. Hard depth hoar did not form in the sample that was allowed to remain isothermal, although sintering due to equilibrium metamorphic processes did occur in this sample. These results suggest that the degree of sintering and the resulting hardness of high-density sieved snow samples is a function of the magnitude of the temperatureinduced vapor pressure gradient through the samples.

The results from hardness tests corroborate the results of work by Akitaya (1974), which showed that the degree of development of hard depth hoar in snow samples was depen-
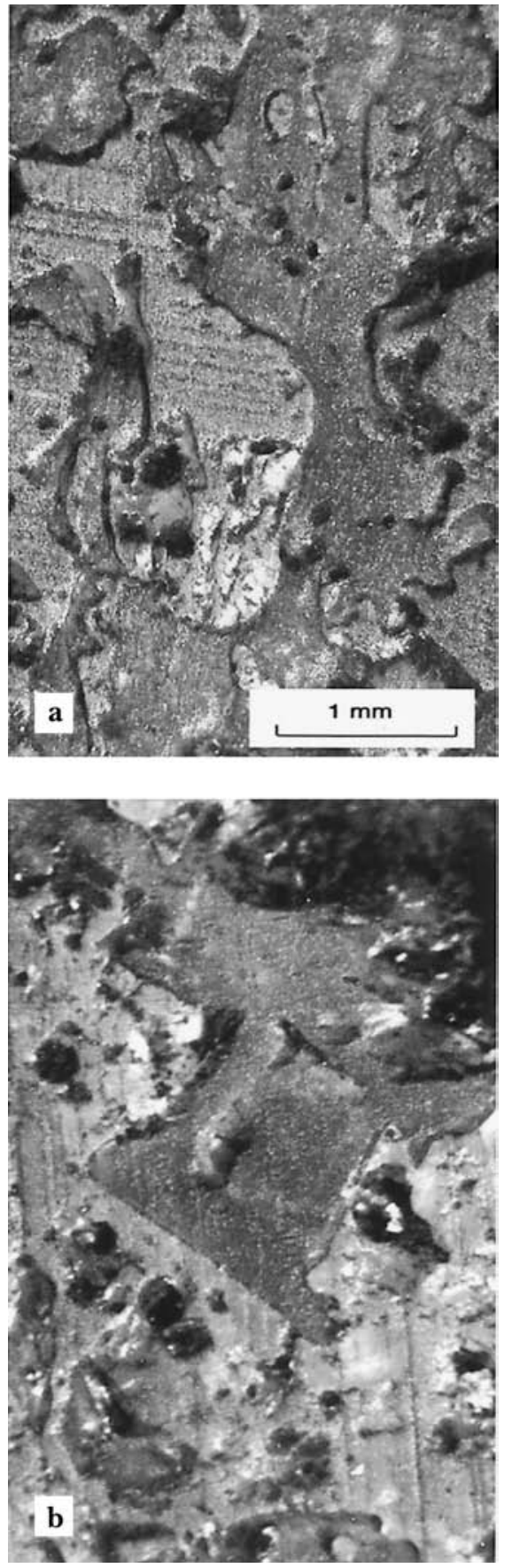

Fig. 11. Section planes prepared from snow taken from under snowmobile trail at the University of Colorado Mountain Research Station, 2 March 1997, at elevation 2900 m. Bottom of snow sample was $3 \mathrm{~cm}$ above snow/soil interface. Initial snow density was $340 \mathrm{~kg} \mathrm{~m}^{-3}$. Sections are oriented vertically (parallel to vaporflux) in (a), and horizontally (perpendicular to vaporflux) in (b).

dent on the temperature gradient applied to the sample. Akitaya (1974) showed that hard depth hoar will form in sieved snow samples having a mean temperature of $-7^{\circ} \mathrm{C}$ and initial density of $420 \mathrm{~kg} \mathrm{~m}^{-3}$ at temperature gradients $>39^{\circ} \mathrm{C} \mathrm{m}^{-1}$. However, Akitaya (1974) found that similar snow samples actually decreased in hardness when exposed to temperature gradients $<30^{\circ} \mathrm{C} \mathrm{m}^{-1}$. Experimental results from this study show that hard depth hoar will form in samples of high-density sieved snow at a temperature gradient as low as $20^{\circ} \mathrm{C} \mathrm{m}^{-1}$. The absolute temperature level may also have had an influence on hardness, since Akitaya (1974) noted differences in hardness with varying temperature over the range $-7^{\circ}$ to $-20^{\circ} \mathrm{C}$. A series of experiments in which tem- 
perature gradient is manipulated while the mean temperature is kept constant would help to resolve this question.

\section{Effects of original snow type and density on the formation of depth hoar}

Experiments in which different snow types and densities were exposed to a $40^{\circ} \mathrm{C} \mathrm{m}^{-1}$ temperature gradient provide evidence that the type of depth hoar that forms is related to the original snow type and density. Solid-type depth hoar formed in all of the samples, but hard depth hoar developed only in the high-density $\left(400 \mathrm{~kg} \mathrm{~m}^{-3}\right)$ sieved snow. The sample of rounded-grain snow having a density of $230 \mathrm{~kg} \mathrm{~m}^{-3}$ was sufficiently sintered at the end of the experimental run to be able to be removed from the sample tube as one piece (Figs 7 and 8). However, neither the strength nor the characteristic oriented grain structure (e.g. Fig. 3c and d) of hard depth hoar was evident in these samples. Incohesive solidtype depth hoar formed in the samples of low-density fresh snow $\left(32 \mathrm{~kg} \mathrm{~m}^{-3}\right)$ and boot-packed fresh snow $\left(192 \mathrm{~kg} \mathrm{~m}^{-3}\right)$.

These results indicate that the formation of hard depth hoar is dependent on snow density. Also, since snow density is dependent on the regularity of the shape of the snow grains (Edens and Brown, 1991), the type of depth hoar that forms is also dependent on grain shape. It should also be noted that the 230 and $400 \mathrm{~kg} \mathrm{~m}^{-3}$ samples used in this study both consisted of rounded grains. Therefore, a critical density presumably exists between these two values above which hard depth hoar will form in rounded-grain snow.

Results of this study also suggest that hard depth hoar formed only in the sample that had the smallest pore spaces between snow grains, corresponding to the highest density. The presence of large pore spaces within a snow cover (Akitaya, 1974; McClung and Schaerer, 1993), combined with a temperature gradient $>10^{\circ} \mathrm{Cm}^{-1}$ (Armstrong, 1985), promotes the formation of solid- and skeleton-type depth hoar. Also, Colbeck (1993) reports that there is an inverse relationship between the diffusion coefficient for snow and the average pore size. Since vapor flux is dependent on the magnitude of the diffusion coefficient and the temperature-induced vapor pressure gradient (Perla, 1978; Armstrong, 1985; Sommerfeld, 1987), an increased effective diffusion coefficient, due to smaller pore size, must cause the vapor flux to be high enough for the formation of hard depth hoar at a temperature gradient of $40^{\circ} \mathrm{C} \mathrm{m}^{-1}$.

\section{Effects of compaction}

Compaction of snow throughout a winter season appears to bring about the conditions necessary for the development of hard depth hoar. As work by Edens and Brown (1991) has shown, assuming spherical grain shapes, compression of snow can cause a 3.5-fold increase in the 3-D coordination number accompanied by pore collapse within the snow. Compaction by snowmobiles at the study site most likely caused a substantial change in grain morphology and therefore an increase in the number of bonds per grain as well as a decrease in pore space. This, combined with an increase in temperature gradient (due to a reduction in snow depth), gave rise to conditions that were ideal for the development of hard depth hoar.

Destruction of the branches of snow crystals may also be necessary for hard depth hoar to develop. In this study, hard depth hoar did not form in the cold-room experiment in which boot-packed snow was exposed to a $40^{\circ} \mathrm{C} \mathrm{m}^{-1}$ tem- perature gradient. Although the snow density was increased to $192 \mathrm{~kg} \mathrm{~m}^{-3}$ by boot packing, most of the stellar arms and dendrites on the original crystals were preserved.

\section{CONGLUSIONS}

Akitaya (1974) hypothesized that hard depth hoar is either an assemblage of minute solid- or skeleton-type depth-hoar grains, or a third completely different type of depth hoar. Results from this study indicate that hard depth hoar consists of faceted solid-type depth-hoar grains joined by necks.

Grain-to-grain bonds (necks) in hard depth hoar appear to form in chains oriented parallel to the direction of vapor flux. The formation of necks between depth-hoar grains is evidently dependent on a vapor pressure gradient (Akitaya, 1974) and therefore on the temperature gradient that is present through the snow. The dependence of the formation of necks on applied temperature gradient gives rise to a correlation between hardness (a proxy for compressive strength) and the magnitude of the applied temperature gradient.

Whether or not hard depth hoar forms within a snow cover exposed to a temperature gradient depends on the original snow type and density. A very hard cohesive form of depth hoar was observed to form from rounded-grain snow having a density of $400 \mathrm{~kg} \mathrm{~m}^{-3}$ or greater, following exposure to a temperature gradient of $20^{\circ} \mathrm{C} \mathrm{m}^{-1}$ or greater.

Compaction of a snow cover leads to densification and can lead to formation of hard depth hoar if compaction alters the original grain morphology of precipitated snow such that the number of bonds per grain is increased and the overall porosity is decreased. Densification of snow by compaction increases the snowpack-scale temperature gradient by reducing the thickness of the snow separating cold air from warm ground. Densification also increases bond density and thereby the bulk thermal conductivity, although regardless of the values of the thermal conductivity, the steady-state temperature gradient will still be the temperature difference between the air and ground surface divided by snowpack thickness. The most important temperature gradient for vapor transport - that crossing pores between grains - is controlled predominantly by changes in pore size, with the gradient increasing with decreasing pore size.

\section{Potential for further research}

In experimental samples in which hard depth hoar formed, there appeared to be very little difference in hardness (compressive strength) in directions parallel vs normal to vapor transport, although this was not investigated systematically. It may be interesting to look at the differential shear strength of samples of hard depth hoar in directions parallel and normal to vapor flux.

Delicate intergranular bonding is easily disrupted by the introduction of a casting pore filler, and consequently little work has been done involving the preparation of section planes from low-density snow. If an improved method can be developed by which casts can be prepared from fresh snow in order to show the arrangement of stellar and dendritic crystals within a snow cover, examination of delicate crystal and grain structures may provide visible evidence for the role of stellar arms and dendrites as depositional sites (Sommerfeld 1985, 1987) for the development of solid- and skeleton-type depth hoar. 


\section{ACKNOWLEDGEMENTS}

This work was supported by the U.S. Army Research Office under Award No. DAAH04-96-1-0033. We thank H. Spetzler for input and comments, and R. L. Armstrong for comments and for the use of photomicrography equipment. We also thank the Associate Editor and two anonymous reviewers, who provided detailed and valuable comments.

\section{REFERENCES}

Akitaya, E. 1974. Studies on depth hoar. Contrib. Inst. Low Temp. Sci., Ser. A 26. Alley, R. B., E. S. Saltzman, K. M. Cuffey and J. J. Fitzpatrick. 1990. Summertime formation of depth hoar in central Greenland. Geophys. Res. Lett., 17 (12), 2393-2396.

Armstrong, R. L. 1985. Metamorphism in a subfreezing, seasonal snow cover: the role of thermal and vapor pressure conditions. (Ph.D. thesis, University of Colorado.

Arons, E. M. and S. C. Colbeck. 1995. Geometry of heat and mass transfer in dry snow: a review of theory and experiment. Rev. Geophys., 33(4), 463-493.

Bear, J. 1988. Dynamics of fluids in porous media. Mineola, NY, Dover.

Bloeschel, G. 1999. Scaling issues in snow hydrology. Hydrol. Processes, 13, 2149-2175.

Bradley, C. C., R. L. Brown and T. R. Williams. 1977. Gradient metamorphism, zonal weakening of the snow-pack and avalanche initiation. 7. Glaciol., 19 (81), 335-342.

Brzoska, J.-B., B. Lesaffre, C. Coléou, K. Xu and R. A. Pieritz. 1999. Computation of 3D curvature on a wet snow sample. The European Physicalfournal. Applied Physics, 7, 45-57.

Colbeck, S. C. 1983. Theory of metamorphism of dry snow. F. Geophys. Res., 88(C9), 5475-5482.

Colbeck, S. C. 1993. The vapor diffusion coefficient for snow. Water Res. Res., 29(1), 109-115.

Colbeck, S. C. and 7 others. 1990. The international classification for seasonal snow on the ground. Wallingford, Oxon, International Association of Scientific Hydrology. International Commission on Snow and Ice.

Cuffey, K. M. and E. J. Steig. 1998. Isotopic diffusion in polar firn: implications for interpretation of seasonal climate parameters in ice-core records, with emphasis on central Greenland. F. Glaciol., 44(147), 273-284.

Edens, M. Q. and R. L. Brown. 1991. Changes in microstructure of snow under large deformations. F. Glaciol., 37(126), 193-202.

Good, W. 1987. Thin sections, serial cuts and 3-D analysis of snow. International Association of Hydrological Sciences Publication 162 (Symposium at Davos 1986 - Avalanche Formation, Movement and Effects), 35-48.

Good, W. 1989. Laboratory techniques for the characterization of snow structure. In Hunt, J. and T. D. Guyenne, eds. International Workshop on Physics and Mechanics of Cometary Materials, October 9-11, 1989, Münster, Westfalia, Germany. Proceedings. Noordwijk, European Space Agency, 147-151. (ESA SP-302.)

McClung, D. M. and P. A. Schaerer. 1993. The avalanche handbook. Seattle, WA, The Mountaineers.

Perla, R. 1978. Temperature-gradient and equi-temperature metamorphism. In Proceedings of the 2nd International Conference on Snow and Avalanches, Grenoble, France, 12-14 April 1978. Association Nationale pour l'Étude de la Neige et des Avalanches, 43-48.

Perla, R. 1982. Preparation of section planes in snow specimens. F. Glaciol., 28(98), 199-204.

Perla, R. 1985. Snow in strong or weak temperature gradients. Part II: Sectionplane analysis. Cold Reg. Sci. Technol., 11(2), 181-186.

Perla, R. and C. S. L. Ommanney. 1985. Snow in strong or weak temperature gradients. Part I: Experiments and qualitative observations. Cold Reg. Sci. Technol., 11(1), 23-35.

Sommerfeld, R. A. 1985. Temperature gradient weakening in snow. USDA For. Serv. Res. Note RM-449.

Sommerfeld, R. A. 1987. Temperature gradient driven vapor transport in snow. USDA For. Serv. Gen. Tech. Rep. RM-149.

Sommerfeld, R. A. and E. LaChapelle. 1970. The classification of snow metamorphism. 7. Glaciol., 9(55), 3-17.

Underwood, E. E. 1970. Quantitative stereology. Reading, MA, Addison-Wesley Publishing.

MS received 25 May 1999 and accepted in revised form 14 August 2002 